\begin{tabular}{|llll} 
P1: SFK/UKS & P2: SFK/UKS & QC: SFK/UKS & T1: SFK \\
BLBK046-Cox & July 24, 2008 & $13: 46$ &
\end{tabular}

\title{
3 Barriers to Effective Pain Management
}

\author{
Eloise Carr
}

\section{Key Messages}

- Patients often have poor understanding regarding pain management, which results in low expectations of pain relief and satisfaction with inadequate pain control.

- The experience of pain has long been accepted as an inevitable part of surgical intervention, but new understanding reveals a dynamic and complex nervous system which can change in response to unrelieved pain, potentially leaving permanent damage and chronic pain.

- Health care professionals often lack appropriate knowledge, attitudes and skills to effectively manage pain due to inadequate education.

- Local hospital regulations and policies may inadvertently inhibit the effective management of pain by causing unnecessary delays to the timely administration of analgesics.

- Globally, many people are denied good pain relief due to some countries' inability to effectively import and distribute morphine for medical reasons.

\section{Introduction}

The management of pain is almost one and the same as perioperative care as it has been reported as the second most common nursing intervention (Junttilla et al.2005). Pain after surgery has been reported to be a consistent problem, which has spanned several decades (Marks \& Sachar 1973, Seers 1987, Svensson et al. 2000, Wu et al. 2002). Nearly half $(n=67)$ of 145 patients admitted to a postanaesthesia care unit experienced severe pain within a 30-min postoperative period (Ekstein et al. 2006). The reasons for this are well documented and include patient barriers, inadequate knowledge of health care professionals, lack of assessment and organisational practices which frequently impede the administration of analgesics and non-pharmacological interventions. Despite this knowledge, the changes required in practice are not necessarily forthcoming. 
\begin{tabular}{|llll} 
P1: SFK/UKS & P2: SFK/UKS & QC: SFK/UKS & T1: SFK \\
BLBK046-Cox & July 24, 2008 & $13: 46$ &
\end{tabular}

\section{Perioperative Pain Management}

This chapter explores how patient as well as professional and organisational barriers affect the optimal management of pain in the perioperative period and provides some practical solutions to reduce these challenges and manage pain more effectively.

\section{Patient barriers}

These can be organised into two important areas. The first relates to anxiety and its relationship to the experience of pain and the second are factors that prevent patients reporting their pain.

In a study investigating patients' knowledge of common medical terms and their surgical care, findings revealed that many held misconceptions about pain management and a significant number were unaware that the anaesthetist was medically qualified (Laffey 2000). It is important to recognise how familiar we may be with our hospital world, but for many it remains a frightening mystery.

\section{Anxiety and pain}

The period prior to surgery can be an extremely anxious time, with concerns regarding the availability of a bed on admission to hospital, the fear of dying under the anaesthesia, fear of pain and for some the possibility of cancer. High levels of anxiety are known to influence the level of pain (Martin 1996, Shi et al. 2003). Many patients come into hospital for surgery expecting pain and often have low expectations about pain relief (Carr \& Thomas 1997, Wickstrom et al. 2005). Previous experiences and stories from family and friends can further elevate anxiety. These raised levels of anxiety often continue in hospital and are exacerbated by rituals such as wearing night clothes during the daytime and lying on trolleys to go to theatre (Carr et al. 2006). Preoperative visits offer an ideal opportunity to explore previous pain experiences, expectations about pain and concerns. Patients who have previously experienced poor pain management in hospital or who are highly anxious will benefit from proactive strategies, such as reassurance, teaching of simple relaxation techniques and being prescribed an anxiolytic agent and analgesics prior to surgery. A Cochrane systematic review on the administration of anxiolytic agents prior to day-case surgery found that they did not delay discharge (Level I: Walker et al. 2003). The inclusion of a rest period prior to and after surgery, which includes soothing music, has been found to be beneficial on patients' anxiety (Level II: Ikonomidou et al. 2004). The acceptance of anxiety in the perioperative period is not helpful and strategies which reduce this unpleasant feeling can have dramatic effects on the reduction of pain following surgery.

Anxious patients may not communicate their feelings openly and may require a recognition that anxiety whilst normal is unpleasant and there are ways of reducing it. Similarly, many patients do not report their pain despite nurses asking them to do so and a range of factors are known to prevent the patient 
\begin{tabular}{|llll} 
P1: SFK/UKS & P2: SFK/UKS & QC: SFK/UKS & T1: SFK \\
BLBK046-Cox & July 24, 2008 & $13: 46$ &
\end{tabular}

\section{Barriers to Effective Pain Management}

from reporting his or her pain even when explicitly asked about. The reasons are many but can include thinking the health care professional is the authority on their pain, distracting the surgeon or anaesthetists from his or her job in treating the problem, a fear of injections, worried about being 'unpopular' and that pain is not actually harmful and can be endured. Pain associated with surgery has frequently been thought to be a relatively short event, which passes, gets better and disappears. Indeed, many patients put up with acute pain, knowing that it is an unpleasant short-term experience but one which will get better - a belief which is often endorsed by those caring for them. Yet emerging knowledge in neurobiology indicates that acute pain may have long-lasting effects on the central nervous system.

Acute pain can be harmful in two ways: by causing a sensitisation to the central nervous system often called 'wind-up' and by causing permanent changes in the way the body perceives pain in future situations.

Inflammatory pain from tissue damage, such as surgery, is conveyed through nerves called nociceptors which send volleys of impulses up the spinal cord to the brain where it is interpreted as pain. Repeated volleys of pain travelling up the spinal cord from surgical intervention can result in sensitivity - the nervous system adapts to the repeated impulses, which results in a sensitisation or 'wind-up'. In the clinical setting you have a patient whose pain is very difficult to control and the normal prescription for analgesics may be insufficient. In pain we often refer to the plasticity of the nervous system, which captures an image of a system which is not static but one which adapts and changes - not always for the better. Those patients who have been depressed or highly anxious appear to have an increased risk of wind-up occurring (Haythornthwaite et al. 1998).

Acute pain which is not relieved can leave an 'imprint' on the central nervous system, which can make patients' pain difficult to control in future situations. It would seem that the nervous system has been changed and cannot forget the previous pain and those volleys of impulses. Research around the use of pre-emptive analgesia has been one of the major areas of interest in recent years (Gottschalk \& Smith 2001), but the evidence continues to be insufficient (Level I: Moiniche et al. 2002). Asking patients about their previous pain experience and recognising that the role of mood can help identify those who are at risk, coupled with increased vigilance in the perioperative period, can hopefully reduce the potential harm that pain can evoke.

Sometimes small noxious stimuli may result in amplification of the incoming nociceptive impulses also known as 'hyperalgesia'. This can lead to 'allodynia', where gently stroking of a certain area of skin can produce immense pain out of all proportion to the stimuli. You may remember a patient who has woken up in agony and quickly becomes frightened and distressed. Their pain is difficult to control and they may require large amount of opioids to gain comfort. This state of affairs has been called 'central sensitisation' and is a state of hyperactivity of the central nervous system. The beliefs of patients (and professionals) that pain, especially acute pain, is short term and will eventually go away without 
\begin{tabular}{|llcc} 
P1: SFK/UKS & P2: SFK/UKS & QC: SFK/UKS & T1: SFK \\
BLBK046-Cox & July 24, 2008 & $13: 46$
\end{tabular}

\section{Perioperative Pain Management}

Table 3.1 Surgical intervention and its association with the development of chronic or persistent pain.

Incidence of chronic pain following surgery $(\%)$

- $30-85 \%$ amputation

- $11-57 \%$ mastectomy

- $13-38 \%$ breast augmentation

- $0-63 \%$ inguinal hernia repair

- 5-67\% thoracotomy

Visser (2006).

harming them is a myth. This needs to be dispelled as pain is harmful and can leave long-term damage. We are beginning to see a nervous system which has 'plasticity' or the ability to change its response depending on the stimulus.

The development of a second type of pain following a surgical intervention may be 'neuropathic' pain and is related to nerve damage during surgery. Whilst pre-emptive analgesics have had variable success in trials, recent research suggests that the period of nerve blockade should be extended to reduce the likelihood of these changes occurring (Xie et al. 2006). The use of a preoperative neuropathic analgesic, such as pregabalin, is likely to be helpful for some surgical patients. There are many examples where acute, poorly controlled pain can develop into chronic or persistent pain (Visser 2006) (see Table

Tab.3.1 3.1 for the associated incidence of chronic/persistent pain following different surgical procedures).

It is important that patients are told that pain can be harmful and a simple explanation of how it can change the way the brain perceives pain. Many patients in pain lie still to avoid the pain and discomfort associated with coughing, deep breathing and moving around, which can contribute to complications postoperatively, such as deep vein thrombosis, chest infection, increased anxiety and even depression. Information for patients should include advice about why it is important to take analgesics to relieve pain enough for them to participate in simple mobilisation and take comfortable deep breaths. This knowledge will motivate them to report pain and not underplay their discomfort.

In summary, patients entering hospital are likely to be very anxious and this may affect their pain. Proactive measures, such as preoperative visits, which explore such anxieties and offer simple relaxation strategies can be helpful. It is important to educate patients that pain is not harmless and should be reported rather than endured. Unrelieved pain can leave permanent changes in the central nervous system, which may precipitate the development of chronic pain.

\section{Professional barriers}

The management of pain in clinical practice has been problematic for many years. For nearly 30 years there have been studies highlighting the inadequacies 
of acute pain management in hospitals and pointing fingers at professionals who lack the knowledge and harbour unhelpful attitudes. Particular deficits have been identified around inadequate knowledge, lack of assessment and documentation, and an unwillingness to raise the priority of pain. These then become 'professional barriers' to good pain management. Some of these are potentially exacerbated further in the perioperative period where patients may not be able to communicate easily; thus, the assessment of pain has become a major concern. Woven into the arena is the nature of the work and especially the need to communicate effectively with other health professions. In this next section, these are the two aspects are focused on, in particular what can be done to reduce these barriers.

\section{Assessing pain}

Pain assessment is the cornerstone of pain management as it forms the basis for decisions about interventions and their evaluation. Yet, in clinical practice, the evidence that pain continues to be problematic continues. The development of tools suitable for patients in the perioperative period as important but the integration of these tools into clinical algorithms which both recognise the complexity of decision-making and permit flexibility in analgesic administration are essential components.

Despite the importance of pain assessment, several authors have written detailed paper considering the management of acute pain and why it continues to be problematic (Schafheutle et al. 2001, Sloman et al. 2005, Twycross 2002). As well as, surgery routine actions during the delivery of care may elicit intense pain, also known as procedural pain, for many patients. A large multicentre study supported by the American Association of Critical Care Nurses, with a sample of 6000 acutely or critically ill patients, identified six common procedures that elicited pain and distress (Puntillo et al. 2001). Table 3.2 illustrates that pain is very prevalent.

In addition to the likelihood that perioperative patients will experience pain, surveys of health professionals continue to find poor knowledge levels

Table 3.2 Six of the most common procedures eliciting pain and distress for acute or critically ill patients.

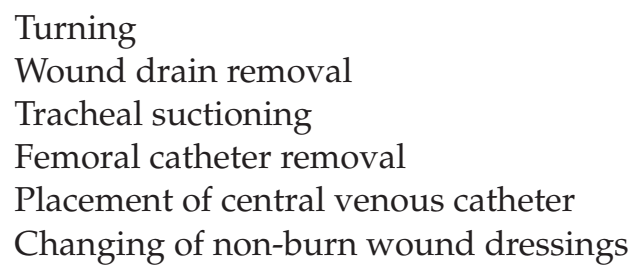

Puntillo et al. (2001). 
\begin{tabular}{|llcr} 
P1: SFK/UKS & P2: SFK/UKS & QC: SFK/UKS & T1: SFK \\
BLBK046-Cox & July 24, 2008 & $13: 46$
\end{tabular}

\section{Perioperative Pain Management}

(Chiu et al. 2003, Coulling 2005) and studies concerning beliefs about pain continue to highlight misconceptions, such as neurologically impaired infants feeling less pain (Breu McGrath 2006). Knowledge, beliefs and attitudes comprise a dominant combination which can impede the delivery of good interventions. In addition to the knowledge and attitudes held by professionals is the 'culture' of a particular clinical area. If, for example, practitioners are not encouraged to give opioids intravenously or staff holds rigid or inappropriate views about pain, it is unlikely that effective pain management will occur. In addition to these factors is that assessing pain in people who are not able to communicate easily is notoriously difficult. Whilst reliance on observation and behaviour are important, the utilisation of a reliable and valid pain assessment tool is essential.

As previously discussed (Chapter 2), pain assessment tools which have been specifically designed for the patient population using them, should be used. For example a pain assessment tool which has been developed for use in people who are unable to communicate a verbal response is the pain assessment and intervention notation (PAIN) tool, which has been developed and used in critical care nursing (Puntillo et al. 2002).

The uniqueness of this assessment tool is that it specifically seeks to address the barriers which may inhibit the effective management of pain in patients being cared for in the critical care unit. In the first section, the assessment focuses on pain behaviours which might be observed and the associated physiological pain indicators, such as movement, facial cues, posture and guarding. Based on these observations, the nurse then makes an overall assessment of how intense they think the patient's pain is. If able, the patient is asked to rate their current pain on a scale of $0-10$. The following section is particularly important as it assesses for potential problems of administering an opioid (blood pressure, heart rate, respirations etc.) and then asks for an 'analgesic treatment decision'. This facilitates the nurse to assess and make a decision about analgesic administration. The nurse caring for a patient recovering from surgery is often in a difficult position as decisions to give further analgesics are often compromised by concerns about the haemodynamic status and sedation level. By explicitly recognising these patient factors, which the nurse takes into account, the final session of the sheet prompts the nurse to consider various treatment options. It is an excellent example of an assessment tool which recognises the complexity and challenges of pain management in clinical practice and addresses this through a practical tool which is educationally supportive.

The assessment of pain and incorporation of treatment decisions can be integrated into a clinical algorithm, which can be very useful in pain management. Such algorithms may include analgesic interventions through the use of patient group directions (PGDs).

PGDs are written instructions, signed by a doctor and a pharmacist, and authorised by the organisation in which they are to used. These include the supply and administration of named medicines (including some controlled drugs) by specified health professionals in an identified clinical situation. In 
\begin{tabular}{|llll} 
P1: SFK/UKS & P2: SFK/UKS & QC: SFK/UKS & T1: SFK \\
BLBK046-Cox & July 24, 2008 & $13: 46$ &
\end{tabular}

\section{Barriers to Effective Pain Management}

Box 3.1 Department of Health consultation document on controlled drugs (March 2007).

22 March 2007: Pain relief made easier: publication of consultations on improving patients' access to medicines

The Government is today launching two consultations that aim to make it easier for patients to get the medicines they need by allowing the prescribing of controlled drugs by nurse independent prescribers and pharmacist independent prescribers; and the supply and/or administration of morphine and diamorphine under Patient Group Directions by nurses and pharmacists for the immediate necessary treatment of sick or injured persons.

Department of Health. http:/www.dh.gov.uk/en/Policyandguidance/ Medicinespharmacyandindustry/Prescriptions/TheNon-Medical

PrescribingProgramme/index.htm. Accessed 27 July 2007.

March 2007, the Department of Health published a consultation documentation which proposed several changes which would bring pain relief more quickly to patients (see Box 3.1). Widening the scope of prescribing, and in particular the ability of nurses to prescribe opioids, is welcome as it is likely to facilitate effective pain management. The contribution of such initiatives is discussed later on in this chapter when organisational aspects are considered.

\section{Communication with other health care professionals}

The development and implementation of clinical algorithms usually entail several different professionals working together. The outcome of such work integrates good practice and provides a document which permits the practitioner to assess and manage pain more effectively. One of the major barriers to good pain management is the effective communication between the different professionals. Interesting research has identified what has been happening in practice.

Margo McCaffery and Betty Ferrell are two nurses with a passion to improve pain education. They conducted a range of studies in the 1980s and revisited their original questions to ask 'how much improvement have we made?' (McCaffery \& Ferrell 1997). Whilst several studies revealed that knowledge levels had improved, the actual practice or management showed less development. This was demonstrated by observational studies in the clinical setting, which gave a better understanding of what is actually happening (Dihle et al. 2006). Elizabeth Manias and her colleagues in Australia have conducted a series of observational studies in practice. Their observational studies found a complex environment which impeded nurses delivering good pain management, constant interruptions and nurses' reliance on assessing pain only whilst taking observations and competing demands, e.g. the doctor's requirement for the patient to be in an uncomfortable position whilst having a drain removed. 
\begin{tabular}{|llll} 
P1: SFK/UKS & P2: SFK/UKS & QC: SFK/UKS & T1: SFK \\
BLBK046-Cox & July 24, 2008 & $13: 46$ &
\end{tabular}

\section{Perioperative Pain Management}

Other studies have pointed to insufficient cooperation by doctors and inadequate prescription of analgesic medications (Titler et al. 2003, Van Niekerk \& Martin 2003). The clinical arena is complex and the relationships with colleagues are crucial as decisions concerning a patient are rarely reliant on one person's judgement and actions. The processes are frequently woven between different professionals, especially when pain begins to escalate.

These difficulties can be partly overcome by ensuring that nurses are confident to communicate with medical staff on the pain management of their patient. I recently heard of the difficulties facing recovery staff when a particular anaesthetist was reluctant to prescribe adequate pain relief for his patients, resulting in many waking from anaesthesia in pain and distress. Despite requests he was would not reconsider his prescribing, a major barrier for effective pain relief. There may be many reasons for this; a survey of anaesthesia clinicians concerning their use of regional analgesia revealed that many overrated the risk of complication, and whilst $100 \%$ said they used or would allow this technique, in practice only $6 \%$ actually did (Boyd et al. 2006). So an audit was undertaken over a 1-month period. All anaesthetists were assigned a letter to ensure that anonymity and pain scores on 'waking' from anaesthesia and at 10-min intervals were recorded for all patients for the first hour. These were transferred to simple graphs and hung in a prominent place. Interestingly, a great deal of interest in the scores emerged and discussion began as to 'how did B manage his list so well' and 'what does P do that makes them all so sick?' It was an excellent way of illuminating difficulties and also facilitating discussion and the identification of good practices. Too often complaints of poor practice are not handled well as people may feel intimidated or lack the evidence to support their concerns. Quite often the 'evidence' is readily available and can be used to start helpful conversations about how to work together to improve care.

More junior members of the team may struggle to communicate the needs of their patients confidently. A technique which can be helpful is using role-play

Box 3-2 (see Box 3.2). It is an invaluable teaching approach which, if used well, can help practitioners feel more confident.

Interprofessional education has been espoused as a way of helping different professionals learn together and improve their collaborative skills, but early research in the field was poor, which meant little could be concluded from the studies published (Level II: Zwarenstein et al. 2001). More recent work has suggested a growing amount of evidence with outcomes from interprofessional education, including improved teamwork, better communication and collaboration ( Level I: Barr et al. 2005). Short meetings, may be at the end of a clinical round, using a patient case study can be a great way of learning together. Study days, which include a range of professionals, invariably allow new understanding of each other's role and clarification of new knowledge and understanding.

This section has considered how assessment and communication with other health care professionals contribute to the barriers evident in managing pain. In concluding this section, I am left with an uncomfortable question - why 
\begin{tabular}{|llcc} 
P1: SFK/UKS & P2: SFK/UKS & QC: SFK/UKS & T1: SFK \\
BLBK046-Cox & July 24, 2008 & $13: 46$ &
\end{tabular}

Barriers to Effective Pain Management

Box 3.2 Role-play for communicating inadequate pain management.

Set the scene
You take the part of a junior anaesthetist on a busy recovery unit and ask
your junior colleague or student to role-play him- or herself. They have
been looking after a young man who is just waking up following
extraction of wisdom teeth. His pain is not well controlled and despite
having had the maximum dose of I.V. morphine prescribed $(15 \mathrm{mg})$, he
still has pain, is restless and calling out with a BP of $145 / 85 \mathrm{~mm} \mathrm{Hg}$.
What usually happens
Student: Dr... Mr Thomas is in a great deal of pain. Can he have
something more?
Doctor: Well he's had the maximum prescription. See how he goes and
let me know if it doesn't settle.
Student: Reluctantly returns to the patient....
The crux of the problem is that the doctor doesn't have enough
information to be able to make a decision. The nurse is also blocked -
having to go back to the poor patient without any more analgesic.
How to get more analgesics prescribed
Student: Dr... Mr Thomas woke up 10 min ago following extraction of
four wisdom teeth. He was very anxious and gave a verbal pain score
of $8 / 10$. I gave 15 mg I.V. morphine but he says his pain score is still
$8 / 10$. His respirations are 26 and regular and oxygen saturation $98 \%$.
Could you prescribe a further 15 mg I.V. I can titrate in 5 -mg
increments against his pain? I'd like him to be comfortable and have a
score of $2-3 / 10$ before going back to the ward.
Dr: That seems a good idea.

has education and the professional preparation of practitioners failed to equip health care professionals with good knowledge about pain management? I pose some responses. For one reason it is not mandatory to include any education on pain in pre-registration training and education. There have been numerous studies highlighting the inadequacies of pain content in the nursing curricula (Coulling 2005, McCaffery \& Ferrell 1997), as well as other health professionals including medicine pharmacy (Lebovitz et al. 1997), occupational therapy (Strong et al. 1999) and physiotherapy (Scudds \& Solomon 1995) across a variety of countries. A review of 50 nursing textbooks concluded that pain content was limited (Ferrell et al. 2000).

In Coulling's study she found when questioning nurses about where they gained their pain knowledge from, the majority stated that it was attained following registration (through journals, professional updates etc.). This suggests that qualified practitioners rely on their professional journals for information and knowledge about pain management. It is surprising then that a recent scan 
\begin{tabular}{|llcc} 
P1: SFK/UKS & P2: SFK/UKS & QC: SFK/UKS & T1: SFK \\
BLBK046-Cox & July 24, 2008 & $13: 46$
\end{tabular}

\section{Perioperative Pain Management}

Table 3.3 Most frequently covered clinical topics in AORN, July 2006-June 2007 (9 issues).

\begin{tabular}{|lc|}
\hline Topic & Number of articles \\
\hline Patient safety & 10 \\
Infection control & 8 \\
Surgical techniques & 8 \\
Health promotion/public health & 5 \\
Medicine administration & 4 \\
Deep vein thrombosis & 3 \\
Managing complications & 2 \\
Preoperative anxiety & 2 \\
Hypothermia & 2 \\
Instruments & 2 \\
Resuscitation & 1 \\
Laboratory diagnostics & 1 \\
Continuous infusion local anaesthetics & 1 \\
Screening techniques & 1 \\
Septic shock & 1 \\
Total & 1 \\
\hline
\end{tabular}

of clinical articles in the American Journal of Operating Room Nursing (AORN) from July 2006 to June 2007, given an average of 6 per issue, resulted in 52 opportunities, but just 2 were published on pain management (Banks 2007, Vaughn et al. 2007) (see Box 3.2). The paucity of articles dedicated to pain management in the perioperative setting seems at odds with the study by Junttilla et al. (2005), who found that 'performing pain management' was the second most important nursing intervention in the perioperative area (see Table 3.3). Comparing Box 3.2 and Table 3.3 reveals a strong congruence with the activities performed by nurses and the articles published in a professional journal. However, the notable exception appears to be those articles related to pain management, given how many perioperative nurses perform this activity. Clearly, the activity and the theory are at odds and one of the 'barriers' appears to be a lack of publication in pain management. Perhaps, this book will stimulate an avalanche of interest and publications will increase exponentially.

\section{Organisational barriers}

The organisation within which pain management takes places often imposes a number of restrictions which may inadvertently hinder the effective management of pain. These can relate to accountability for pain management, local 
Barriers to Effective Pain Management

Table 3.4 The 10 most common perioperative nursing interventions.

\begin{tabular}{|lr|}
\hline Perioperative nursing interventions & Number (\%) \\
\hline Maintaining body temperature & $344(10 \%)$ \\
Performing pain management & $239(7 \%)$ \\
Preventing risks/perioperative injury & $165(7 \%)$ \\
Monitoring fluid volume & $160(5 \%)$ \\
Monitoring & $147(4 \%)$ \\
Preventing risk for impaired skin integrity & $146(4 \%)$ \\
Supporting patient's perioperative coping & $135(4 \%)$ \\
Administering medicines & $114(3 \%)$ \\
Implementing aseptic technique & $104(3 \%)$ \\
Providing information about anaesthesia/procedure & $103(3 \%)$ \\
Total & $1700(49 \%)$ \\
\hline
\end{tabular}

Junttilla et al. (2005).

culture, trust or hospital policies regarding drug administration and resources available (see Table 3.4). Beyond the hospital, national policies can influence the availability of analgesics by restricting the prescribing or influencing service provision. There are also global barriers which affect pain management, such as influencing the importation of opioids. These policies have received considerable attention in recent years as it is increasingly recognised that these restrictions reduce the quality of life for many people including those in European countries (Blengini et al. 2003).

\section{Accountability}

Over 30 years ago, The Politics of Pain Management by Fagerhaugh \& Strauss (1977) was published. The text detailed a research study involving observation and interviews with staff and patients in a hospital, with a consideration of how the organisation in which pain control took place influenced the patients' experience. They concluded that the discrepancy between actual pain relief and the potential was due to work demands in the clinical area, lack of accountability surrounding the management of pain and the complexity of the patient/staff relationship. In the perioperative area, who is accountable for pain management - the anaesthetist, surgeon, acute pain team, registrar, the nurse caring for the patient or indeed the patient? It is often difficult to determine exactly who is accountable as the person may change during the course of the patient's journey. Clear lines of accountability and communication are important aspects of pain management. Personally, I take the stance that the nurse is accountable for he or she is with the patient around the clock and is potentially in the most prominent position to influence the care for that person. Whilst recognising that they may not always be in a position to prescribe 


\section{Perioperative Pain Management}

(although this is changing), they can influence and often have flexibility to decide on analgesic administration and non-pharmacological strategies to ameliorate pain.

The organisation in which we work can be powerful in tempering the 'norms' of practice. This moves beyond an individual's response to a person in pain but reflects a social collective where certain groups of patients may be disadvantaged in terms of the quality of their pain management. For example it has been found that ethnic group may influence analgesic practice (Todd et al. 2000) and older people in surgical settings may also not always fair as well as their younger counterparts (Prose 2007). There is also limited data to support the view that women are more likely to be undertreated for their pain than are men (Hoffmann \& Tarzian 2001, McNeill et al. 2004).

\section{Local policies}

Despite the best will (and knowledge), sometimes local policies can inhibit effective pain management. These policies are frequently part of the rules and regulations and are rarely challenged. One example of a common hospital policy is where two nurses are required to check a controlled drug. Many hospitals continue to use this policy and indeed many nurses feel that this makes the administration of these drugs safer. In reality, errors are well documented even when two people check the drug, as part of the problem lies in the range of other factors that might contribute, such as poorly written prescriptions (Anderson \& Webster 2001). The requirement for two nurses to check a controlled drug is not a legal one (Royal Pharmaceutical Society of Great Britain 2005). Another routine ritual is the blanket rule that morphine cannot be carried on a drug trolley, yet the oral preparation of $10 \mathrm{mg} / 5 \mathrm{~mL}$ does not fall into the same legal requirements for storage as those of other opioids. This preparation can be carried on a drug trolley for immediate administration, rather than taking the prescription and saying 'we'll come back later'. This often results in a delay, which means someone enduring further pain for perhaps another 30-40 min.

Reflect on your local policies and assess whether they hinder you in delivering analgesics. It might be helpful to time how long it takes to prepare and administer the analgesics over the period of a week by keeping a note on a piece of paper. All you need to do is note the start time (identifying patient in pain) and end time (giving analgesics). This information can be helpful when requesting a review of policy.

\section{Local resources}

Resources available to us such as access to high-quality analgesics, an epidural service and the availability of patient controlled analgesia all form part of our local resources. It has been reported, not surprisingly, that barriers such as 
\begin{tabular}{|llll} 
P1: SFK/UKS & P2: SFK/UKS & QC: SFK/UKS & T1: SFK \\
BLBK046-Cox & July 24, 2008 & $13: 46$
\end{tabular}

Barriers to Effective Pain Management

workload and lack of staff impede pain management (Schafheutle et al. 2001). The advent of acute pain teams in hospitals has done a great deal to improve local acute pain management and would be considered a prime resource. The continuing fiscal demands in the National Health Services (NHS) have revealed the vulnerability of some of these teams and their activities have sometimes been curtailed or devolved to other professionals in an attempt to save money. Inadequate resources become a barrier to the effective delivery of pain management and monitoring the quality of patients' experiences of pain through audit activity can change the perspective. Too often, staff feel disempowered or anxious that patients' negative experiences may reflect badly upon them and are inhibited to reveal the extent of a problem. Ensuring that pain assessment (and documentation) and management are integrated in local audit activity is crucial if pain management is to be improved and appropriate resources given to support it.

The US developed a strategy to help change the management of pain by documenting the assessment of pain as the 'fifth vital sign' in an attempt to change heighten awareness and change behaviour (Berdine 2002). The Joint Commission on Accreditation of Health Care Organisations (2001) published a set of standards for accreditation in American hospitals. These standards provide a framework for good-quality pain management and can highlight areas where resources may be inadequate. For example the provision of a dedicated pain management team and a formal quality programme are cited as a standard. It is helpful to use published standards such as these in measuring performance and identifying areas for improvement. The importance of linking audit to improvement activities in pain management has been explored and there are published examples how this has been done (Carr 2002, Gordon \& Dahl 2004, Stomberg et al. 2003). Critically look at local documents and note where pain assessment and information relating to interventions are recorded. Is pain assessment and documentation a routine part of care-does it appear as the fifth vital sign? These sorts of questions start to address barriers and identify areas for quality improvement work.

Harnessing published guidelines, on the management of pain, and linking these with your own audit activity is a powerful combination. In the UK, it begins to shift the culture of acceptance to challenge and enquiry. It focuses on learning about what is actually happening in practice and you will soon see lots of opportunities for small changes which have the potential to improve care.

\section{National perspectives - new legislation on prescribing}

One of the major barriers repeatedly reported in the literature, over several decades, has been associated with nurses who care for people experiencing pain and responsible for the safe administration of their analgesics but who are unable to prescribe or review them for the patient. Experienced nurses talk 
\begin{tabular}{|llll} 
P1: SFK/UKS & P2: SFK/UKS & QC: SFK/UKS & T1: SFK \\
BLBK046-Cox & July 24, 2008 & $13: 46$ &
\end{tabular}

\section{Perioperative Pain Management}

of their role in educating junior doctors and their prescribing of analgesics. The modernisation of the NHS and a review of nursing roles have helped to push forward legislation to widen prescribing beyond the medical practitioner. These changes in legislation and their influences on local policy are welcome as it will help remove barriers which impede effective and timely administration of analgesics. There are three key developments worth mentioning in relation to pain, supplementary prescribing, independent nurse prescribing and PGDs.

Supplementary prescribers are nurses, pharmacists, chiropodists/ podiatrists, physiotherapists and radiographers who have undergone specialist training. They are permitted to prescribe any NHS medicine, provided it is in partnership with an independent prescriber who establishes the initial diagnosis and starts the treatment. The supplementary prescriber then monitors the patient and prescribes further supplies of medication when necessary. Initially aimed at chronic disease management in primary care, there has been a call for consideration in acute settings if the benefits are to be realised (Fitzpatrick 2004).

In May 2006, qualified nurse independent prescribers (previously known as extended formulary nurse prescribers) were permitted to prescribe any licensed medicine for any medical condition within their competence, including some controlled drugs. As noted earlier in this chapter, there is a possibility that the recent consultation on prescribing will result in an opening of the gate to widen prescribing access for nurses (and dentists) to include opioids across several patient groups, including postoperative and trauma. A recent national advert for an advanced perioperative practitioner required the applicant to work as an independent prescriber and give oral and parental medicines. The pace of change is fast and a range of health care professionals are eligible to take forward these changes in prescribing. Pain management is a central activity for clinicians working in the perioperative setting and ripe for development in this context.

\section{Global barriers and policies}

The increasing globalisation of health care is pertinent to the management of pain in the perioperative period as many countries strive to deliver high-quality care within tight fiscal policies. Rapid advancements in technology promise a range of improvements, such as reduced operating times and shorter inpatient stay. Acute pain guidelines published in Australia and New Zealand (Australian and New Zealand College of Anaesthetists, Faculty of Pain Medicine 2005) have utility and resonance with health care organisations thousands of miles away. Yet many countries continue to face barriers to delivering effective pain relief - not just of inadequate technology and facilities but in the inability

Fig.3.1 to relieve pain through the fundamental use of opioids. Figure 3.1 shows a selection of countries and the $\mathrm{mg} /$ per capita use of morphine. 


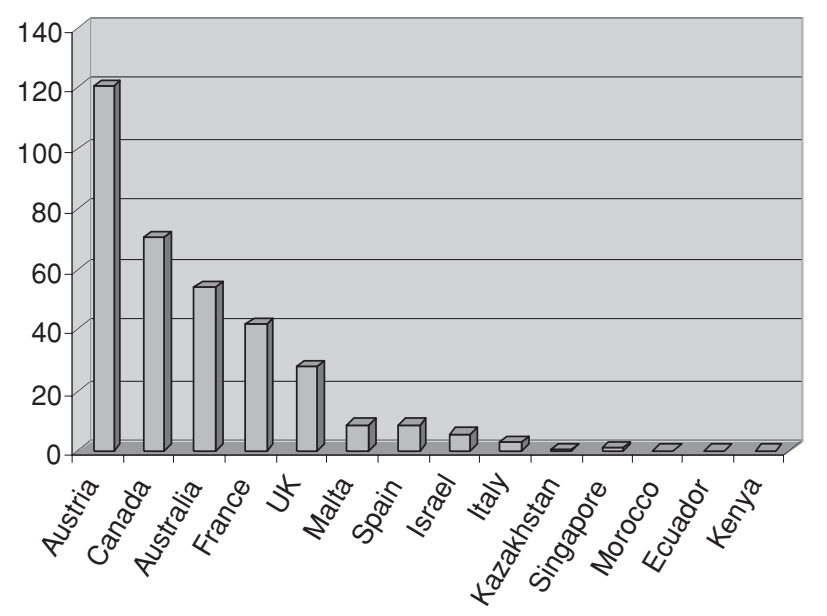

Figure 3.1 Selected countries' $\mathrm{mg} /$ capita from the International Narcotics Control Board (2005).

A recent paper highlighted the numerous barriers India faced when importing opioids for the management of pain (Rajagopal \& Joranson 2007). These included requirements for several licences to procure one consignment of morphine, inadequate health profession knowledge and interruptions to morphine supplies. The Pain and Policy Studies Group, at the University of Wisconsin, has been instrumental in working with governments around the world to streamline regulations and policies which conspire to inhibit pain relief. Whilst much of their focus is within palliative care, there is recognition that such policies also limit the availability of opioids following surgery and many people undergo major surgical intervention without adequate postoperative pain relief. In the International Narcotics Control Boards Annual Report for 2004 (International Narcotics Control Board 2004, p. 24), they stated that the global use of narcotics for medical purposes was inadequate and identified three main reasons: unnecessarily strict rules and regulations, inappropriate attitudes by health care professionals and a lack of economic means and resources to treat pain.

It is salutary to reflect on the difficulties faced by many countries in their endeavours to provide opioids to people in pain. Many of the barriers which exist in the UK have not been provided by national regulations but are due to local interpretation and bureaucracy - thus self-imposed. It is only by critically reflecting on local policies and procedures and identifying those which impede or prevent timely administration of analgesics that this can be improved.

\section{Conclusion}

This chapter has brought together a range of patient, professional and organisational barriers which can impede the effective management of pain in the 


\begin{tabular}{|llll} 
P1: SFK/UKS & P2: SFK/UKS & QC: SFK/UKS & T1: SFK \\
BLBK046-Cox & July 24, 2008 & $13: 46$
\end{tabular}

\section{Perioperative Pain Management}

perioperative area. Anxiety is a major concern as it can have a detrimental effect on the experience of pain and is often amenable to pharmacological and nonpharmacological intervention. The experience of pain has long been accepted as an inevitable part of surgical intervention, but new understanding reveals a dynamic and complex nervous system which can change in response to unrelieved pain which can leave permanent damage. Professionals often endeavour to deliver good pain management, but inappropriate attitudes, beliefs and poor communication between those in the perioperative field can mitigate effective care. Beyond the vicinity of the perioperative arena is the organisation in which this care is carried out. Local regulations and policies can conspire to delay or impede the delivery of good-quality pain management. Practitioners may feel frustrated and powerless to do anything but accept the status quo. Improving pain management is more than good knowledge and clinical skills. It requires practitioners to continually ask critical questions, communicate openly with other professionals and recognise the wider organisational context in which care takes place.

\section{References}

Anderson, D.J. \& Webster, C.S. (2001) A systems approach to the reduction of medication errors on the hospital ward. Journal of Advanced Nursing, 35 (1), 34-41.

Australian and New Zealand College of Anaesthetists, Faculty of Pain Medicine (2005) Acute Pain Management: Scientific Evidence, 2nd edn. Australian and New Zealand College of Anaesthetists, Melbourne. http://www.anzca.edu.au/publications/ acutepain.htm. Accessed 30 July 2007.

Banks, A. (2007) Innovations in postoperative pain management: continuous infusion of local anesthetics. Association of Perioperative Registered Nurses Journal (AORN), 85 (5), 904-914.

Barr, H., Koppel, I., Reeves, S., Hammick, M. \& Freeth, D. (2005) Effective Interprofessional Education: Argument, Assumption and Evidence. Blackwell, Oxford.

Berdine, H.J. (2002) The fifth vital sign: cornerstone of a new pain management strategy. Disease Management and Health Outcomes, 10 (3), 155-165.

Blengini, C., Joranson, D.E. \& Ryan, K.M. (2003) Italy reforms national policy for cancer pain relief and opioids. European Journal of Cancer Care, 12 (1), 28-34.

Boyd, A., Eastwood, V., Kalynych, N. \& McDonough, J. (2006) Clinician perceived barriers to the use of regional anaesthesia and analgesia. Acute Pain, 8 (1), 23-27.

Breau, L.M., McGrath, P., Stevens, B., Beyene, J., Camfield, C., Finley, G.A., Franck, L., Gibbins, S., Howlett, A., McKeever, P., O’Brien, K. \& Ohlsson, A. (2006) Judgments of pain in the neonatal intensive care setting: a survey of direct care staffs' perceptions of pain in infants at risk for neurological impairment. Clinical Journal of Pain, 22 (2), 122-129.

Carr, E., Brockbank, K., Allen, S. \& Strike, P. (2006) Prevalence and patterns of anxiety in patients undergoing gynaecological surgery. Journal of Clinical Nursing, 15 (3), 341352. 
\begin{tabular}{|llll} 
P1: SFK/UKS & P2: SFK/UKS & QC: SFK/UKS & T1: SFK \\
BLBK046-Cox & July 24, 2008 & $13: 46$
\end{tabular}

\section{Barriers to Effective Pain Management}

Carr, E.C.J. (2002) Refusing analgesics: using continuous improvement to improve pain management on a surgical ward. Journal of Clinical Nursing, 11 (6), 743-752.

Carr, E.C.J. \& Thomas, V.J. (1997) Anticipating and experiencing post-operative pain: the patients' perspective. Journal of Clinical Nursing, 6 (3), 191-201.

Chiu, L.H., Trinca, J., Lim, L.M. \& Tuazon, J.A. (2003) A study to evaluate the pain knowledge of two sub-populations of final year nursing students: Australia and Philippines. Journal of Advanced Nursing, 41 (1), 99-108.

Coulling, S. (2005) Nurses' and doctors' knowledge of pain after surgery. Nursing Standard, 19 (34), 41-49.

Department of Health (2007) Pain Relief Made Easier: Publication of Consultations on Improving Patients' Access to Medicines. Department of Health, London.

Dihle, A., Bjolseth, G. \& Helseth, S. (2006) The gap between saying and doing in postoperative pain management. Journal of Clinical Nursing, 15 (4), 469-479.

Ekstein, P., Szold, A., Sagie, B., Werbin, N., Klausner, J.M. \& Weinbroum, A.A. (2006) Laparoscopic surgery may be associated with severe pain and high analgesia requirements in the immediate postoperative period. Annals of Surgery, 243 (1), 41-46.

Fagerhaugh, S.Y. \& Strauss, A. (1977) Politics of Pain Management: Staff-Patient Interaction. Addison-Wesley Publishing Company, Menlo Park, CA.

Ferrell, B., Virani, R., Grant, M., Vallerand, A. \& McCaffery, M. Analysis of pain content in nursing textbook. Journal of Pain and Symptom Management, 19, 216-228.

Haythornthwaite, J.A., Menefee, L.A., Heinberg, L.J. \& Clark, M.R. (1998) Pain coping strategies predict perceived control over pain. Pain, 77 (1), 33-39.

Hoffmann, D.E. \& Tarzian, A.J. (2001) The girl who cried pain: a bias against women in the treatment of pain. Journal of Law and Med Ethics, 29 (1) 13-27.

Ikonomidou, E., Rehnström, A. \& Naesh, O. (2004) Effect of music on vital signs and postoperative pain. American Operating Registered Nurse Journal, 80 (2), 269-274, 277278.

Joint Commission on Accreditation of Health Care Organisations (2001) Pain Management Standards. http://www.jointcommission.org. Accessed 30 July 2007.

Junttilla, K., Salantera, S. \& Hupli, M. (2005) Developing terminology for documenting perioperative nursing interventions. International Journal of Medical Informatics, 74 (6), 461-471.

Fitzpatrick, R. (2004) It is time we shared good practice in supplementary prescribing? Hospital Pharmacist 11, 442.

Gordon, D.B. \& Dahl, J.L. (2004) Quality improvement challenges in pain management. Pain, 107 (1-2), 1-4.

Gottschalk, A. \& Smith, D.S. (2001) New concepts in acute pain therapy: preemptive analgesia. American Family Physician, 63 (10), 1979-1984.

International Narcotics Control Board (2004) Annual Report. http://www.incb.org/ incb/annual_report_2004.html. Accessed 6 August 2007.

International Narcotics Control Board (2005) Annual Report. http://www.incb.org/ pdf/e/ar/2005/incb_report_2005_full.pdf. Accessed 6 August 2007.

Laffey, J.G., Coleman, M. \& Boylan, J.F. (2000) Patients' knowledge of perioperative care. Irish Journal of Medical Science, 169 (2), 113-118.

Lebovitz, A.H., Florence, I., Bathina, R., Hunko, V., Fox, M. \& Bramble, C. (1997) Pain knowledge and attitudes of health care providers: practice characteristic differences. Clinical Journal of Pain, 13 (3), 237-243. 
\begin{tabular}{|llll} 
P1: SFK/UKS & P2: SFK/UKS & QC: SFK/UKS & T1: SFK \\
BLBK046-Cox & July 24, 2008 & $13: 46$
\end{tabular}

\section{Perioperative Pain Management}

Marks, R.M. \& Sachar, E.J. (1973) Undertreatment of medical inpatients with narcotic analgesics. Annals of Internal Medicine, 78 (2), 173-181.

Martin, D. (1996) Pre-operative visits to reduce patient anxiety: a study. Nursing Standard, 10 (23), 33-38.

McCaffery, M. \& Ferrell, B. (1997) Nurses' knowledge of pain assessment and management: how much progress have we made? Journal of Pain and Symptom Management, 14 (3), 175-188.

McNeill, J., Sherwood, G.D. \& Starck, P.L. (2004) The hidden error of mismanaged pain: a systems approach. Journal of Pain E Symptom Management, 28 (1), 47-58.

Moiniche, S., Kehlet, H. \& Dahl, J.B. (2002) A qualitative and quantitative systematic review of preemptive analgesia for postoperative pain relief. Anesthesiology, 96 (3), 725-741.

Puntillo, K.A., White, C., Morris, A., Perdue, S., Stanik-Hutt, J., Thompson, C. \& Wild, L. (2001) Patients' perceptions and responses to procedural pain: results from Thunder II Project. American Journal of Critical Care, 10 (4), 238-251.

Prowse, M. (2007) Postoperative pain in older people: a review of the literature. Journal of Clinical Nursing, 16 (1), 84-97.

Puntillo, K., Stannard, D., Miaskowski, C., Kehrle, K. \& Gleeson, S. (2002) Use of a pain assessment and intervention notation (P.A.I.N.) tool in critical care nursing practice: nurses' evaluations. Heart Lung, 31 (4), 303-314.

Rajagopal, M.R. \& Joranson, D.E. (2007) India: opioid availability: an update. Journal of Pain Symptom \& Management, 33 (5), 615-622.

Royal Pharmaceutical Society of Great Britain (2005) The Safe and Secure Handling of Medicines: A Team Approach. Royal Pharmaceutical Society of Great Britain, London. Revised Duthie Report of 1988. http://www.rpsgb.org.uk/informationresources/ downloadsocietypublications/. Accessed 30 July 2007.

Schafheutle, E.I., Cantrill, J.A. \& Noyce, P.R. (2001) Why is pain management suboptimal on surgical wards? Journal of Advanced Nursing, 33 (6), 728-737.

Scudds, R. \& Solomon, P. (1995) Pain and its management: a new pain curriculum for occupational therapists and physical therapists. Physiotherapy in Canada, 47 (2), 77-78.

Seers, K. (1987) Pain, Anxiety and Recovery in Patients Undergoing Surgery. PhD Thesis. University of London, London.

Shi, S.F., Munjas, B.A., Wan, T.T., Cowling, W.R., Grap, M.J. \& Wang, B.B. (2003) The effects of preparatory sensory information on ICU patients. Journal of Medical Systems, 27 (2), 191-204.

Sloman, R., Rosen, G., Rom, M. \& Shir, Y. (2005) Nurses' assessment of pain in surgical patients.Journal of Advanced Nursing, 52 (2), 125-132.

Stomberg, M.W., Wickström, K., Joelsson, H., Sjöström, B. \& Haljamäe, H. (2003) Postoperative pain management on surgical wards - do quality assurance strategies result in long-term effects on staff member attitudes and clinical outcomes? Pain Management in Nursing, 4 (1), 11-22.

Strong, J., Tooth, L. \& Unruh, A. (1999) Knowledge about pain among newly graduated occupational therapists: relevance for curriculum development. Canadian Journal of Occupational Therapy, 66 (5), 221-228.

Svensson, I., Sjöström, B. \& Haljamäe, H. (2000) Assessment of pain experiences after elective surgery. Journal of Pain and Symptom Management, 20 (3), 193-201.

Titler, M.G., Herr, K., Schilling, M.L., March, L.J., Xie, X.J., Ardery, G., Clarke, W.R. \& Everett, L.Q. (2003) Acute pain treatment for older adults hospitalized with hip 


\begin{tabular}{|llcc} 
P1: SFK/UKS & P2: SFK/UKS & QC: SFK/UKS & T1: SFK \\
BLBK046-Cox & July 24, 2008 & $13: 46$ &
\end{tabular}

\section{Barriers to Effective Pain Management}

fracture: current nursing practices and perceived barriers. Applied Nursing Research, 16 (4), 211-227.

Todd, K.H., Deaton, C., D'Adamo, A.P. \& Goe, L. (2000) Ethnicity and analgesic practice [Comment]. Annals of Emergency Medicine, 35 (1), 11-16.

Twycross, A. (2002) Educating nurses about pain management: the way forward. Journal of Clinical Nursing, 11 (6), 705-714.

Van Niekerk, L.M. \& Martin, F. (2003) The impact of the nurse-physician relationship on barriers encountered by nurses during pain management. Pain Management Nursing, 4 (1), 3-10.

Vaughn, F., Wichowski, H. \& Bosworth, G. (2007) Does preoperative anxiety level predict postoperative pain? Association of Perioperative Registered Nurses Journal (AORN), 85 (3), 589-594, 597-604.

Visser, E. (2006) Chronic post-surgical pain: epidemiology and clinical implications for acute pain management. Acute Pain, 8 (2), 73-81.

Walker, K.J., Smith, A.F. \& Pittaway, A.J. (2003) Premedication for anxiety in adult day surgery. Cochrane Database of Systematic Reviews, Issue 1, Art No CD002192. DOI: 10.1002/14651858.CD002192.

Wickström, K., Nordberg, G. \& Gaston Johansson, F. (2005) Predictors and barriers to adequate treatment of postoperative pain after radical prostatectomy. Acute Pain, 7 (4), 167-176.

Wu, C., Berenholtz, S., Pronovost, P. \& Fleisher, L. (2002) Systematic review and analysis of postdischarge symptoms after outpatient surgery. Anesthesiology, 96 (4), 994-1003.

Xie, W., Strong, J., Meij, J., Zhang, J.M. \& Yu, L. (2006) Neuropathic pain: early spontaneous afferent activity is the trigger. Pain, 116 (3), 243-256.

Zwarenstein, M., Reeves, S., Barr, H., Hammick, M., Koppel, I. \& Atkins, J. (2001) Interprofessional education: effects on professional practice and health care outcomes (Cochrane review). In: The Cochrane Library 4. Update Software, Oxford. 